\title{
A better code for a better relationship
}

\author{
Russell Williams ${ }^{1}$, Paul C Adams MD², Editor-in-Chief
}

$\mathrm{R}$ ussell Williams is the President of Canada's Research-Based Pharmaceutical Companies ( $\mathrm{x} \& \mathrm{QD}) . \mathrm{Rx} \& \mathrm{D}$ is the national association representing over 22,000 Canadians who work for more than 50 member companies. Member companies share a single primary objective: to discover new medicines that will improve the quality of health care available for every Canadian.

PA: What led up to the changes in the $R x \& D$ Code of Conduct in Canada?

RW: The Code is a living document that expresses our industry's ongoing relationship with health care professionals. The Code is designed to change with evolving market practices, public opinion and best practices around the world.

In this regard, we believed it was time to address further improvements to the Code that would clearly demonstrate industry's commitment to best ethical practices with health care professionals.

PA: When were these changes implemented?

RW: These improvements were implemented

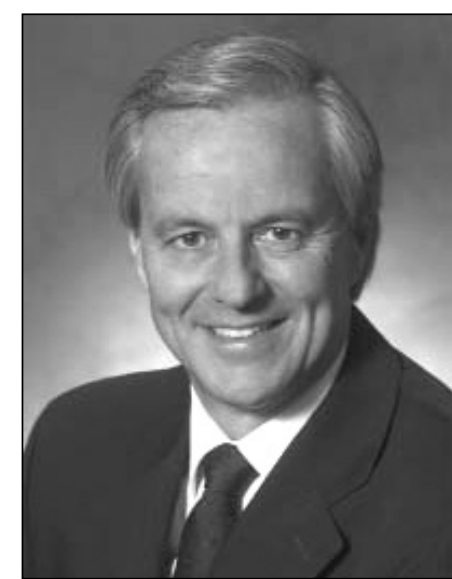

Russell Williams is the President of Canada's Research-Based Pharmaceutical Companies (RxED)

adjudication. The IPRC is composed of experts including industry legal counsel, regulatory and marketing representatives, and two external health care professionals (physician and pharmacist).

Also, Code infractions are made public in two ways: on our Web site, and via our newsletter (RxED Update).

PA: In Germany there have been criminal charges laid against physicians. Could that happen in Canada?

RW: No. The Rx\&D Code of Conduct is not subject to judicial lawsuits because it is a selfregulated code, but mandatory for our member companies.

PA: How do the Canadian changes compare with American guidelines?

RW: In simple terms, adherence to Rx\&D's Code of Conduct is mandatory and a condition of membership in the association. In addition to having reported infractions adjudicated by the IPRC (see response to question 5), companies that have five or more violations in one calendar year or has two successive years with at least three violations in each year will be placed on a 12 -month probationary period by the $\mathrm{Rx} \& \mathrm{D}$ Executive Committee. If the company is found to be in violation of the Code of Conduct during its probationary period, the Board of Directors will determine if the violation is just cause to have the company expelled from $R x \& D$.

In the United States, the Pharmaceutical Research and Manufacturers of America (PhRMA) Code on Interactions with Healthcare Professionals is voluntary and adherence to the Code is not a condition of membership. With respect to the latest changes in the PhRMA Code, your readers are encouraged to visit the PhRMA Web site < www.phrma.org>. PA: Let's go over a few scenarios that may relate to our members in the past and you can advise us on how these would be viewed under the new guidelines.

Most gastroenterologists are avid golfers and they often played golf with pharmaceutical representatives. This may have been the local course or at some of the most famous golf courses in the world. Their travel and golf expenses were often covered because they were having a 'meeting'.

RW: The intent of the recent changes to the Code is to ensure industry's professional interaction with health care professionals is transparent, and eliminates any perception people may have that such invitations are extended to health care professionals solely for the purpose of gaining access to them.

PA: In the above scenario, the physician is designated a referred to the Inder Practices Review Committee (IPRC) fo

${ }^{1}$ Canada's Research-Based Pharmaceutical Companies (Rx\&D); ${ }^{2}$ London Health Sciences Centre, London, Ontario

Correspondence: François Lessard, Director, Communications and Public Affairs, Canada's Research-Based Pharmaceutical Companies,

55 Metcalfe Street, Suite 1220, Ottawa, Ontario K1P 6L5. Telephone 613-236-0455, fax 613-236-6861, Internet www.canadapharma.org 
consultant to the company and now is being paid to attend the meeting on the golf course.

RW: Again, keeping in mind public perception and proper business ethical conduct and the professional relationship between health care professionals and industry, $R x \& D$ concluded that paying green fees for a physician-consultant for a round of golf was not appropriate.

PA: At national meetings, it was quite common for social events to be sponsored by industry.

RW: This is no longer the case. Social events are important, but must not take precedence over the purpose of the meeting: education and exchange of related information.

PA: Do these rules apply to meetings outside of Canada?

RW: Yes.

PA: Another common scenario was for pharmaceutical companies to pay physicians' travel expenses to attend educational seminars in attractive locations in Canada and abroad.

RW: This is no longer the case. Pharmaceutical companies continue to host continuing health education events to ensure physicians have the necessary credits to maintain their license and educate them about new, approved medications.

PA: At our annual Canadian Digestive Diseases Week, speakers that belong to our society do not have travel expenses paid and will often have a very minimal honorarium. At the same meetings, industry-sponsored satellite symposia invite their speakers with luxurious and lucrative speaking and travel arrangements.

RW: Under the Rx\&D Code, a fair and reasonable honorarium may be given to a speaker. Also, companies may provide financial support, for example to physicians, to attend a yearly international continuing health education event provided attendees comply with the stringent requirements outlined in Section 4A of the Code.

PA: Can companies now advertise directly to patients in Canada as we see with American television commercials?

RW: Notwithstanding the fact that Canadian consumers see pharmaceutical advertising and information daily on American television, direct-to-consumer advertising in Canada is not permitted by law, a law which was put in place over 40 years ago.

We believe an informed patient is a healthier patient and is better able to make decisions about his or her health care. $\mathrm{Rx} \& \mathrm{D}$ consulted with Health Canada as part of the federal government's legislative renewal process. As part of our submission, we submitted a "made in Canada" recommendation on the rules governing advertising of prescription medicines in Canada. As of yet, we have not heard back from Health Canada.

PA: The public is becoming increasingly aware of the physician-industry relationship. We have the next Michael Moore movie in progress on this topic. The public is very concerned with the high cost of prescription medications. Where do they fit into this picture?

RW: The physician-industry relationship is an integral part of the global health care system. Physicians prescribe the medicines that are researched and developed by the innovative pharmaceutical community.

In this regard, the public must have every confidence the medicines prescribed to them are based on optimal drug therapy and what is prescribed for them is the best intervention to treat or cure a diagnosed illness. It is paramount that the physician be fully knowledgeable about new approved medicines, updated clinical evidence of existing medicines and any new indications approved by the Therapeutic Products Directorate, Health Canada. This is achieved in various ways, such as direct contact with an informed pharmaceutical representative, continuing health education and professional medical magazines, just to name a few. What is presented to the physician must be unbiased, factual and present all known clinical outcomes.

PA: Many of our members may feel that they are 'entitled' to business perks similar to other executives in business and government? Is this a different situation?

RW: There is no question that ethics and adherence to a high standard of ethics is even more paramount today in professional relationships and interactions at all levels of employment. Canadians will not accept anything less, nor should they.

While health care continues to be the top concern of Canadians, I would not be surprised to see ethics make its way onto the list in the near future. Rightly or wrongly, perception can affect so many outcomes.

With respect to ongoing interactions between industry and health care professionals, in this case physicians, the intent of the Code is in this case, again, to eliminate the perception people may have that any perceived 'perks' were extended to health care professionals solely for the purpose of gaining access to them or to influence them.

PA: Many of our members are concerned that they may have lost an important 'fringe benefit' of their job. I can see the positives for the industry with a more ethical footprint in the public eye. What are the positives for our gastroenterologists?

RW: First of all, not only does industry have an improved Code of Conduct, but with the latest improvements it is even stronger. It is not so much what is positive for one component of the health care profession, but what is positive for the entire medical community in its professional relationship with the pharmaceutical community.

In addition to being a 'win-win' for the medical and pharmaceutical communities, the Code has also had a positive impact with our stakeholders and the public at large.

The Code of Conduct is a living document that has undergone several improvements since it was first introduced 18 years ago. The Code will continue to evolve and grow to reflect our industry's commitment to the highest ethical standards possible.

PA: Where do you think we are headed in the future?

RW: The Code will continually change to reflect everyday standards. This will help us to become more involved as ethical health care planners. We are already recongnized as health care providers but we would like to be fully integrated into the health care planning system. In this regard, we believe our Code will help us build those long-term partnerships with academics, patients, health care officials and health care planners. In addition, we are hopeful the self-regulatory aspects of our Code will inspire governments and encourage other companies and industries that do not have a code of conduct to establish and adhere to such a code in their daily public and business activities. 


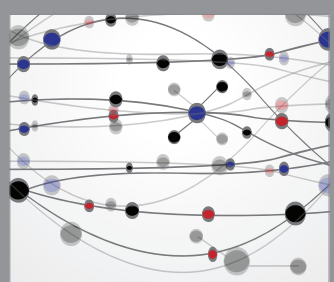

The Scientific World Journal
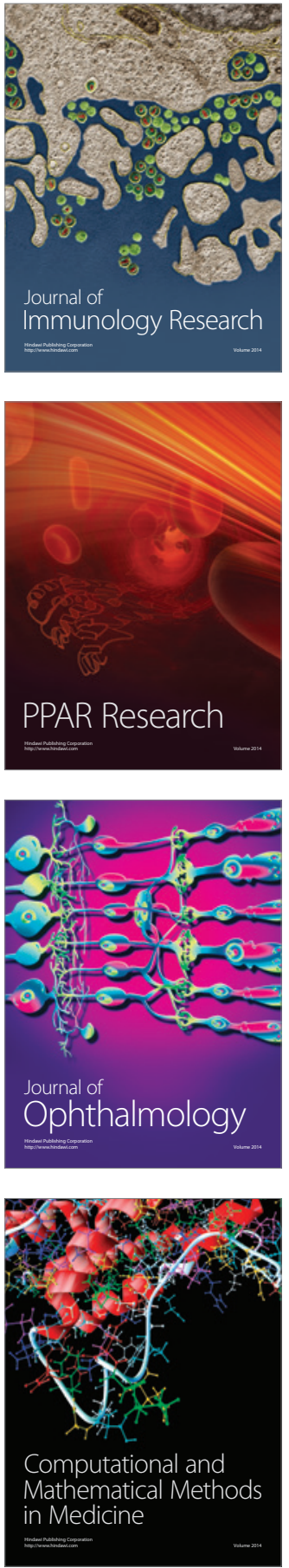

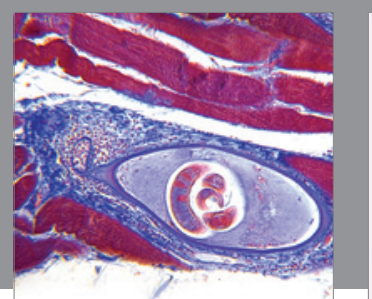

Gastroenterology Research and Practice

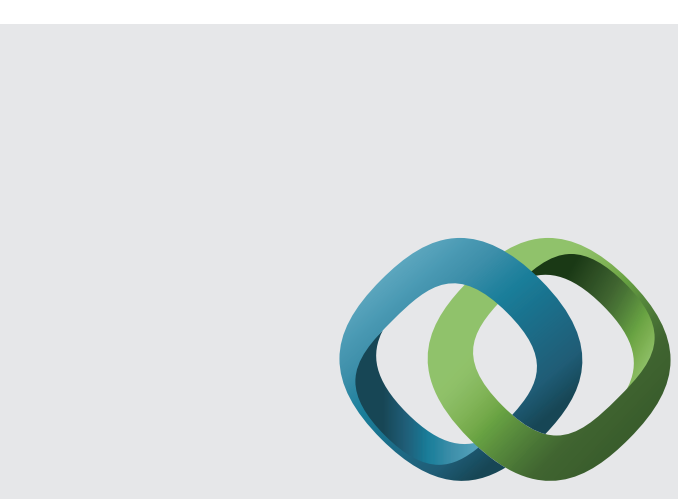

\section{Hindawi}

Submit your manuscripts at

http://www.hindawi.com
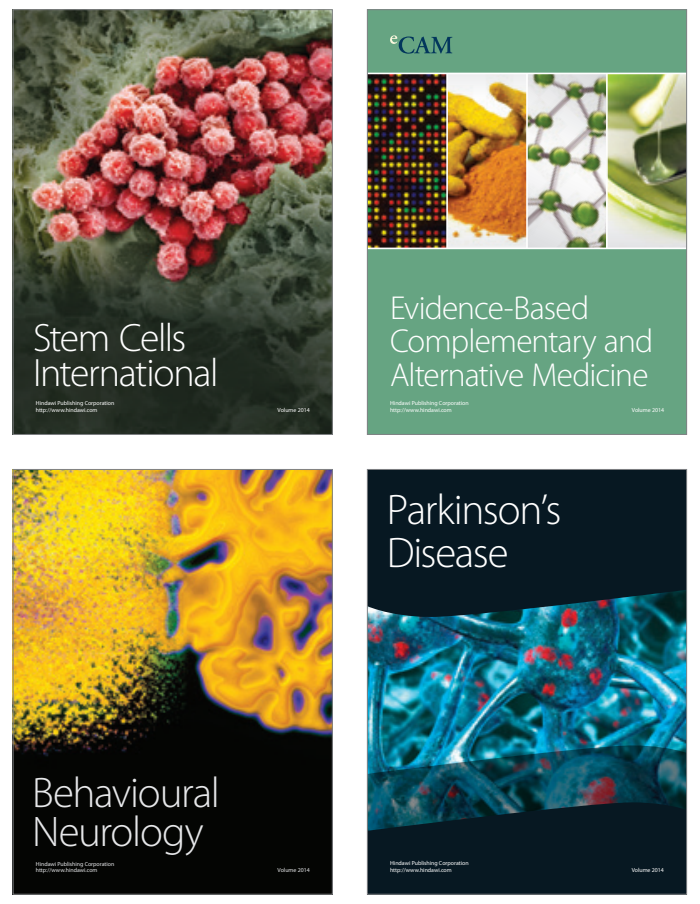
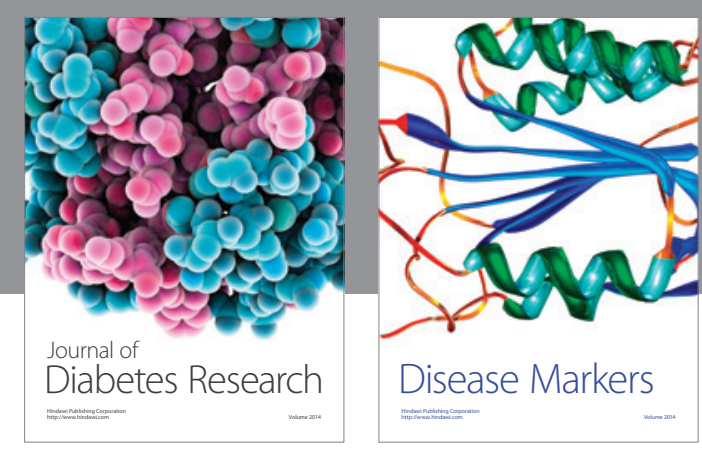

Disease Markers
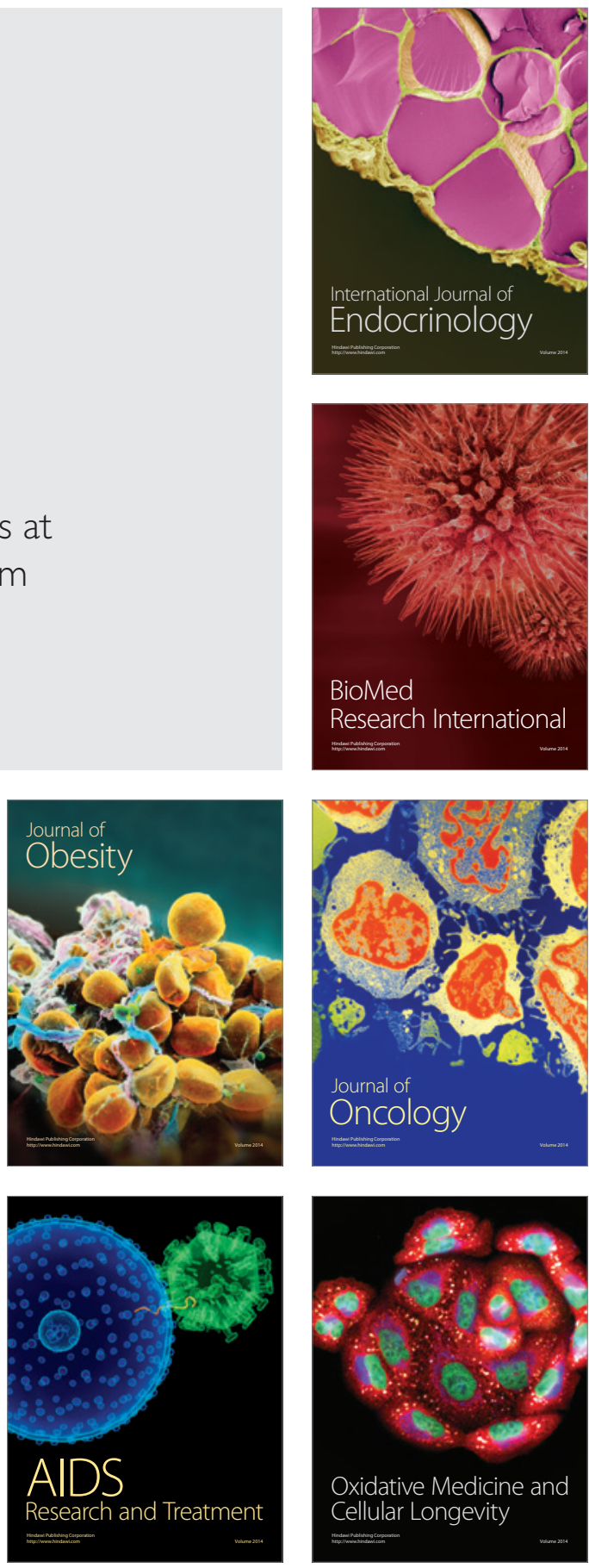